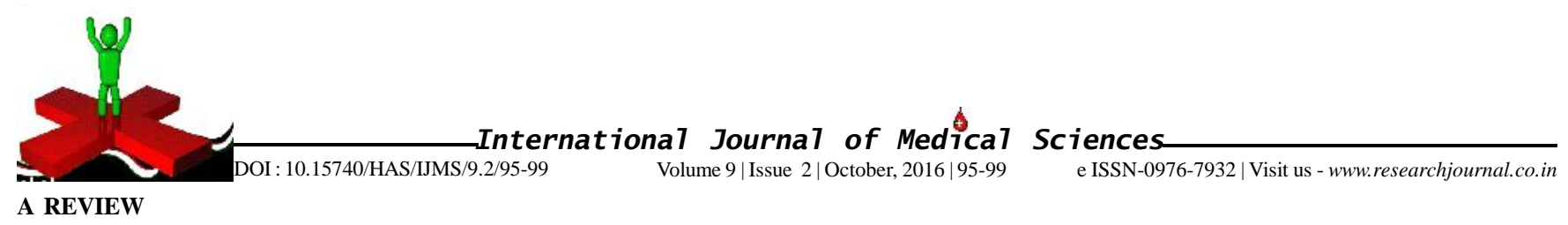

\title{
A Constitutional Approach to Male Infertility
}

\section{ANITA AND BLANY LOBO}

See end of the paper for authors' affiliation

Correspondence to :

ANITA

Department of Repertory, Fr Muller Homoeopathic

Medical College and Hospital, University Road, Deralakatte, MANGALORE (KARNATAKA) INDIA
ABSTRACT : About 8 per cent to 10 per cent of couples of reproductive age experience infertility, and in approximately 40 per cent of these cases male infertility, is the major factor. More than 90 per cent of the male infertility cases are due to low sperm counts, poor sperm quality, or both. Homeopathy is a well-described, scientifically based system which can cure male infertility through a constitutional approach ${ }^{8}$. The investigations have also done before and after treatment to assess the efficacy of the indicated constitutional remedy.

How to cite this paper : Anita and Lobo, Blany (2016). A Constitutional Approach to Male Infertility. Internat. J. Med. Sci., 9(2) : 95-99, DOI : 10.15740/HAS/IJMS/9.2/95-99.

\section{KEY WORDS :}

Constitutional

remedy ${ }^{4}$,

Homoeopathy, Male

infertility 